\title{
A narrative review of diaphragm ultrasound to predict weaning from mechanical ventilation: where are we and where are we heading?
}

Peter Turton ${ }^{1,2^{*}} \mathbb{D}$, Sondus ALAidarous ${ }^{1,3}$ and Ingeborg Welters ${ }^{1,2}$

\begin{abstract}
Background: The use of ultrasound to visualize the diaphragm is well established. Over the last 15 years, certain indices of diaphragm function, namely diaphragm thickness, thickening fraction and excursion have been established for mechanically ventilated patients to track changes in diaphragm size and function over time, to assess and diagnose diaphragmatic dysfunction, and to evaluate if these indices can predict successful liberation from mechanical ventilation. In the last 2 years, three meta-analyses and a systematic review have assessed the usability of diaphragmatic ultrasound to predict successful weaning. Since then, further data have been published on the topic.

Conclusions: The aim of this narrative review is to briefly describe the common methods of diaphragmatic function assessment using ultrasound techniques, before summarizing the major points raised by the recent reviews. A narrative summary of the most recent data will be presented, before concluding with a brief discussion of future research directions in this field.
\end{abstract}

Keywords: Diaphragm, Muscle atrophy, Diaphragm ultrasound, Thickening fraction

\section{Background}

There has been much interest in the use of diaphragm ultrasound as a tool of measuring and tracking atrophy, in particular to identify patients who will wean from mechanical ventilation, and who will remain free of ventilatory support afterwards. Two meta-analyses and a systematic review have been published on the topic in the last 2 years, and more work is being produced. The aim of this narrative review is briefly re-iterate what is being measured with diaphragm ultrasound, to summarize the most recent findings from these reviews and meta-analyses, and to provide an update of current work produced after these reviews.

\section{The diaphragm in critical care: what do we know?}

The effects of atrophy of the diaphragm secondary to mechanical ventilation have been recently described; Goligher found that the development of diaphragm

\footnotetext{
*Correspondence: pturton@liverpool.ac.uk

${ }^{1}$ Critical Care Unit, Royal Liverpool University Hospital, Liverpool, UK

Full list of author information is available at the end of the article
}

atrophy was associated with prolonged duration of mechanical ventilation, increased ICU length of stay, and a higher rate of complications [1]. Interestingly, patients who showed an increase in diaphragmatic thickness during their critical illness were also at higher risk of prolonged mechanical ventilation, with excessive respiratory effort as a possible underlying trigger. The authors did acknowledge that tissue oedema from fluid resuscitation may also contribute to this thickening. Diaphragmatic thickness has been shown to reduce by $6 \%$ [2] or $7.5 \%$ [3] per day in mechanically ventilated patients. However, a further study demonstrated that although nearly half of the patients in their study did suffer atrophy, the same proportion experienced no loss, and a further $10 \%$ actually had increases in diaphragmatic thickness [4]. A recent study in mechanically ventilated children suggested that diaphragmatic atrophy occurs at an average rate of $3.4 \%$ per day and is worsened by the use of neuromuscular blockade [5]. However, two papers failed to demonstrate diaphragmatic atrophy using ultrasound $[6$, 7]. However, one of these studies was in extubated survivors of sepsis $(82 \%$ of which had either severe sepsis or 
septic shock) who were approached after a period of at least 5 days of mechanical ventilation, compared to controls. However, the authors concede that these results were based on a single measurement at a point in the patients' recovery from sepsis rather than during the acute episode.

\section{Ultrasound and the diaphragm}

Visualization of the diaphragm with ultrasound has been possible for well over 40 years [8]. However, only recently diaphragmatic ultrasound has been used to assess diaphragm function and size during mechanical ventilation. There are two commonly used measurements derived from ultrasound: diaphragm excursion and diaphragm thickness [9]. Diaphragm excursion is usually measured using a phased array probe, with the probe positioned in the subcostal margin in the mid-clavicular line, with the aim of imaging the posterior third of the diaphragm (Fig. 1). Although some studies have used B-mode imaging to determine diaphragmatic excursion [10], the use of M-mode produces images that visualize the movement of the diaphragm over time and allows accurate measurement of diaphragmatic displacement over a respiratory cycle (Figs. 2 and 3) [11]. In healthy volunteers, diaphragmatic excursion is known to vary with sex and height and can be reliably performed in a recumbent or supine position [12]. Excursion is known to positively correlate with lung inspiratory volumes [13, 14], and is higher during forced inspiratory breathing [10].

Diaphragm thickness is measured in the zone of apposition, using a higher-frequency ( $>10 \mathrm{MHz}$ ) linear probe, to view the diaphragm as a three-layered structure, sandwiched between the two echogenic layers of the pleura and the peritoneum (Fig. 4) [15]. Both B- and M-mode techniques can be used to measure thickness [16]. Diaphragm thickness has been previously correlated with

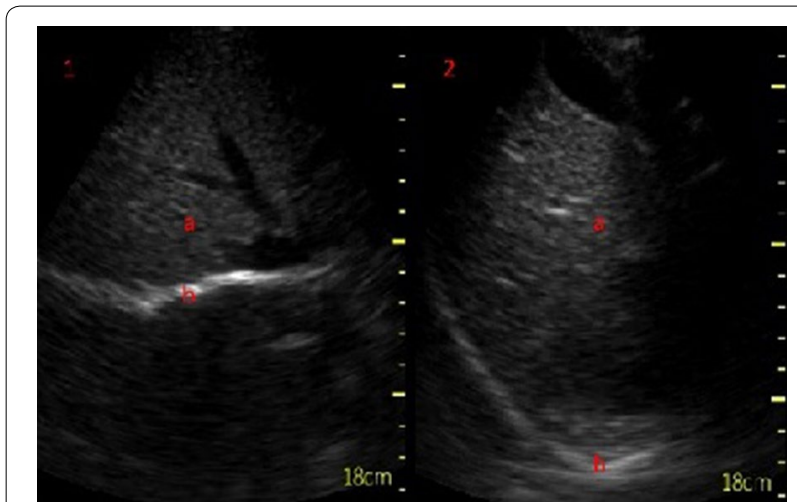

Fig. 1 Subcostal view of the diaphragm (b) in B-mode at end inspiration (1) and at expiration (2) seen below the liver (a)

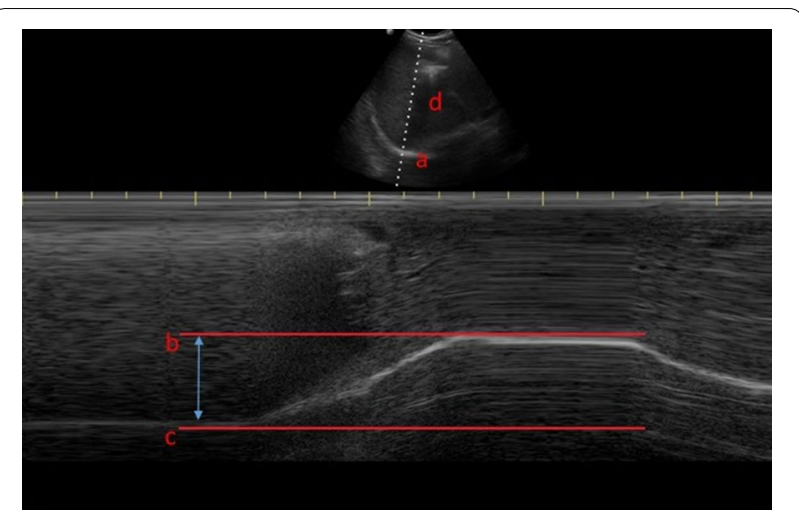

Fig. 2 Diaphragm excursion as assessed via M-mode ultrasonography, where $a$ is the diaphragm, $b$ is at the end of a deep inspiratory effort, $c$ is at end expiration and $d$ is the liver

the strength of the diaphragm [17], but not the endurance or fatigability [18]. It appears to be thicker in an upright position, compared to supine posture [19], can be measured at expiration or end inspiration, and in both tidal and maximal breathing. Comparing expiratory with inspiratory thickness gives the thickening fraction, which is usually denoted as [(End Inspiratory Thickness - End Expiratory Thickness)/End Expiratory Thickness] [20] and is an indicator of the work of breathing [21]. These measurements can be used to form a definition of diaphragm dysfunction, although there is variation in this definition: It has been defined as a thickening fraction of less than $20 \%$ or a tidal excursion of less than $10 \mathrm{~mm}$ [22], based on the presence of paradoxical movement in the case of the paralyzed diaphragm [9], or using non-ultrasound methods such as measurement of twitch pressures [23]. Regardless, ultrasound techniques have been shown to outperform traditional techniques such as fluoroscopy in diagnosing diaphragm dysfunction [24].

\section{Summary of current literature}

In 2017, a systematic review [25] and a meta-analysis [26] have been performed, assessing the evidence on diaphragm ultrasound and its ability to predict successful weaning from mechanical ventilation. Two further meta-analyses have been published in 2018 [27, 28], and together these reviews assessed the combined work of more than 30 individual papers (excluding further 3 papers that looked exclusively at lung rather than diaphragm ultrasound).

The systematic review [25] focused on the use of diaphragmatic ultrasound in four key areas: to diagnose diaphragmatic dysfunction, to predict successful weaning from mechanical ventilation, to determine if ultrasound can assess muscular workload against other known 


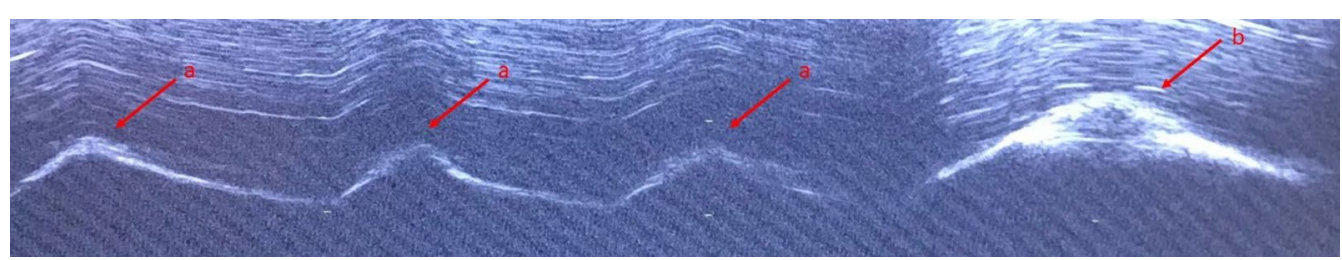

Fig. 3 M-mode ultrasonography demonstrating three tidal inspiratory efforts (a) and a deep inspiratory effort (b)
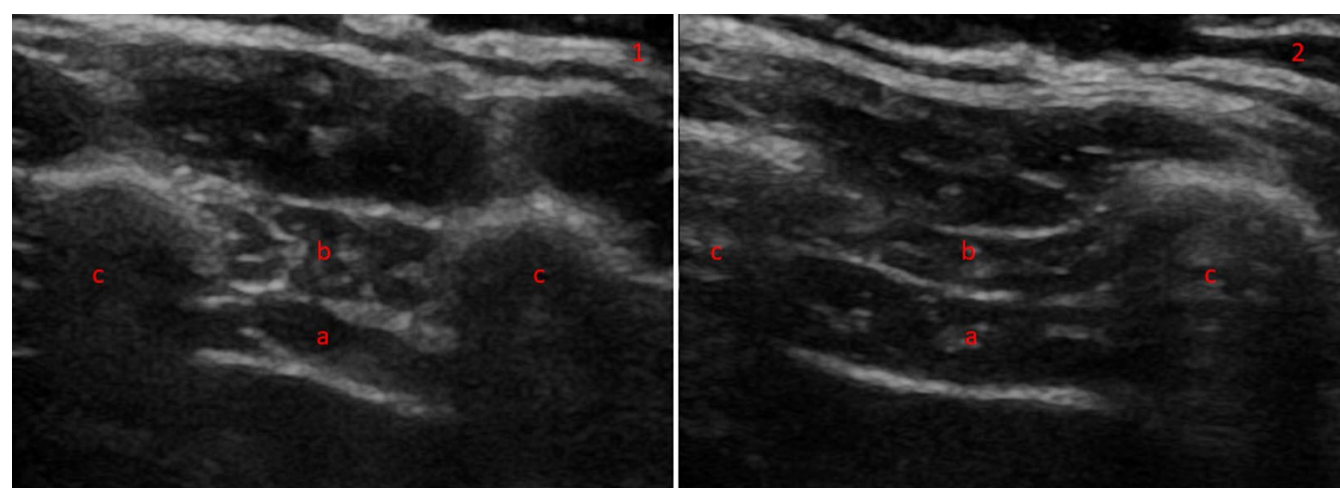

Fig. 4 Diaphragm thickness in B-mode thoracic view at end expiration (1) and inspiration (2) in a heathy volunteer. The diaphragm can be seen between two echogenic layers (a) with the intercostal compartment above (b). The two muscle layers sit between two ribs (c)

measurements such as transdiaphragmatic pressure [29], and to describe variations in diaphragm atrophy across studies.

With respect to weaning from mechanical ventilation, four studies were analyzed, two of which described diaphragm excursion either by M-mode ultrasound [30] or by measuring organ displacement [31]. The two remaining studies assessed diaphragmatic thickening fraction $[32,33]$. All four studies concluded that their respective measurements can predict successful extubation or weaning failure, with cut-off values of 11-14 $\mathrm{mm}$ in excursion and $30-36 \%$ in thickening fraction being most sensitive and specific.

The three meta-analyses are broadly similar in their aims and results. A possible reason may lie in the slight differences to the selection criteria; Li et al. reviewed only publications in English and defined weaning failure as the requirement for re-intubation within $48 \mathrm{~h}$, whereas Llamas-Álverez et al. included publications in all languages and had a much broader definition of weaning failure to include death, unscheduled non-invasive ventilation, tracheostomy formation or the failure of a spontaneous breathing trial within $72 \mathrm{~h}$, and Qian defined weaning failure more broadly as a failed spontaneous breathing trial, re-intubation, the use of non-invasive ventilation, or death. Li and Llamas-Álverez found similar AUC characteristics for the use of diaphragm thickening fraction
(0.83 versus 0.87 ). Llamas-Álverez et al. concluded that thickening fraction may help to predict weaning failure, and $\mathrm{Li}$ et al. concluded that the either measurement is suitable to predict successful extubation. Qian found that pooled specificity for predicting weaning success was similar to the work of Llamas-Âlverez, and also found that weaning failure was higher in the presence of diaphragmatic dysfunction, and that both excursion and thickening fraction were higher in patients who were successfully weaned.

All papers acknowledge the heterogeneity in the studies analyzed. The definition of weaning failure varied amongst individual studies, with re-intubation limits set at either 48 or $72 \mathrm{~h}$, and some studies included the use of non-invasive ventilation to define weaning failure. Inclusion criteria are different for each of the studies; while some studies recruited patients during their first spontaneous breathing trial [32], another study included only patients who had already had a failed trial [33]. Further differences arise from the ultrasonic technique chosen; in Li's meta-analysis, 4 of the studies were conducted with the patient in a supine position, while patients were semirecumbent in the remaining 9 studies. Although probe position was consistent in all studies, probe frequency and ultrasound machine manufacturer varied considerably, with 12 different types of ultrasound machines being used, covering a range of frequencies from 3.5 to $10 \mathrm{MHz}$. 
There is also variation in the patient populations, particularly with respect to age and sex. It is known that age negatively correlates with excursion in deep breathing, and that females have less diaphragmatic excursion [12]. Many of the studies included both left and right sides of the diaphragm, but some reported measurements of the right side only, probably because there is greater difficulty in imaging the left diaphragm due to the lung obscuring the view [13]. Finally, there is variation regarding the time point during a spontaneous breathing trial at which measurements are taken, with ultrasound images being obtained at the start or end of spontaneous breathing; some investigators assessed diaphragmatic function after extubation, others during mechanically ventilation with further variation in the ventilatory mode used. It has been suggested that pre-extubation is the best time to perform diaphragm ultrasound to assess the diaphragm at a time point when it may be fatigued. A protocol for a new study performing ultrasounds at regular intervals throughout $2 \mathrm{~h}$ of spontaneous breathing has been published, but the results are not yet available [34].

\section{Where are we now?}

Since the publication of the systematic reviews, several studies have reported diaphragmatic ultrasound parameters as a means of predicting extubation success. Our search strategy used MEDLINE only; we searched for papers published after 1st January 2017 until to the current date of writing (August 2018). Using the search string (Ultraso* AND Diaphagm* AND (criti$\mathrm{cal}^{*}$ OR intensive OR sepsis OR mechanical * OR ventilat*) yielded 89 results. After having excluded papers that already appeared in the four systematic reviews and papers covering different topics as assessed on title and/ or abstract), we identified 18 new papers since 2017 that have not been part of a systematic review.

\section{Newer studies}

Newly identified studies can be divided into three categories. In the first, there are studies in which diaphragm thickening or excursion are used alone to predict successful weaning. In the second, diaphragm ultrasound is compared to another technique; and in the third, these techniques are combined to see if they increase predictive accuracy.

A recent study describes cut-offs for diaphragm thickening to predict successful weaning prior to a spontaneous breathing trial [35]. Its results are in keeping with previously established cut-offs for patients weaning from pressure support [36]. However, there are also conflicting results. For example, a study evaluating diaphragm excursion using spleen and liver displacement found that displacement of the organs by $1.2 \mathrm{~cm}$ was the best cut-off for predicting successful extubation [37]. However, poor agreement between solid organ movement and diaphragm excursion has been described before [38]. Another recent study found that diaphragmatic excursion, and not thickening fraction, was the best predictor of extubation failure in patients undergoing their first spontaneous breathing trial [39]. The most recent reliability study has established values of inter- $(0.987)$ and intra-observer variability $(0.986)$ that are within the higher range of Intra Class Correlation (ICC) coefficients established in the systematic review [40].

\section{Newer studies-comparative approaches}

Dres and colleagues compared the performance of diaphragm ultrasound against tracheal pressure measurements obtained during supra-maximal phrenic nerve stimulation during a spontaneous breathing trial [23]. They not only found that a lower stimulated pressure than previously accepted was associated with optimum sensitivity and specificity for liberation from mechanical ventilation [41], but also described that a thickening fraction of greater than $25.8 \%$ gave equivalent accuracy of prediction in comparison to phrenic nerve stimulation, with AUC-ROC values of 0.80 and 0.82 for phrenic nerve stimulation and diaphragm thickening fraction, respectively.

\section{Newer studies-combined approaches}

Combining diaphragmatic ultrasound with echocardiography may be a promising route for prediction of successful weaning, particularly in view of potential cardiac causes for a failed respiratory wean [42]. The ratio of mitral Doppler inflow velocity (E) to annular tissue Doppler wave velocity (Ea, E/Ea ratio) has been measured with transthoracic echocardiography alongside diaphragmatic excursion in patients who were extubated after a successful spontaneous breathing trial (SBT) [43]. The authors found that respiratory failure within $48 \mathrm{~h}$ of extubation could be predicted from both $E / E$ a and left ventricular ejection fraction values, but that reintubation within a week of extubation was more accurately predicted by diaphragmatic excursion.

Another study combined echocardiography with lung ultrasound and assessment of diaphragmatic excursion to assess if all three combined could predict extubation failure in patients undergoing a trial of pressure support ventilation [44]. The results were confirmed in a smaller sub-study of patients breathing via a T-tube, although out of the three modalities, diaphragm ultrasound contributed least predicting successful weaning. Furthermore, a recent small observational study has combined echocardiography and lung ultrasound for assessment of aeration with diaphragmatic ultrasound, and reported that lung 
aeration and markers of diastolic dysfunction were the only strong predictors of successful extubation [45].

Another combined approach combined diaphragm thickening fraction with the Rapid Shallow Breathing Index (RSBI). First described in 1991 [46], RSBI is defined as the ratio of the respiratory frequency to the tidal volume [47], with a cut-off value of 100-105 breaths/min/ liter being associated with successful extubation [46, 48]. A recent study found that RSBI alone, in comparison to measurements derived from diaphragm ultrasound, was most accurate in predicting success of extubation, with an ROC-AUC of 0.96 and a sensitivity and specificity of $100 \%$ [49]. This supports earlier work that the sensitivity, specificity and positive predictive value of a thickening fraction cut-off $36 \%$ were comparable to RSBI, but ultimately lower than it [33]. However, the combination of RSBI with diaphragm thickening fraction of greater than $26 \%$ was a more accurate predictor of successful weaning from mechanical ventilation than RSBI alone [50]. The authors concluded that thickening fraction of the right diaphragm alone was as accurate as this combined approach, and suggested that thickening fraction could replace RSBI as the most commonly used weaning parameter in the future.

\section{Future directions}

As ultrasound technology progresses, it may be possible for clinicians to estimate diaphragm thickness and excursion using portable, hand-held devices. A recent study used both linear and phased arrays probes of a hand-held ultrasound device to assess diaphragmatic thickness and excursion, respectively, compared to a standard ultrasound device [22]. Good agreement was noted between the two devices, with ICCs of greater than 0.9 noted in all indices of measurement except for maximal excursion. Based on a definition of diaphragmatic dysfunction as tidal excursion of less than $10 \mathrm{~mm}$, the detection of dysfunction was comparable between the two devices, and good inter-rater reliability was also seen. Stronger agreement between the two devices was seen in the measurement of diaphragm thickness compared to measurement of excursion, possibly because of the hand-held device lacking an M-mode for accurate measurement of excursion.

A third measurement, the contraction velocity, has also been evaluated recently. Contraction velocity is an extension of diaphragm excursion, dividing excursion by the time to reach maximal excursion [9]. None of the systematic reviews assessed contraction velocity in the prediction of successful weaning. A study of elderly ventilated patients found that right-sided contraction velocity had a similar AUC as right-sided excursion (labeled in the study as diaphragmatic motion), and that both of these were more predictive for successful weaning from mechanical ventilation than RSBI [51]. Contraction velocity has been shown to have high sensitivity and specificity, and only performed slightly worse than RSBI in a study of younger patients [49]. A more recent study, however, found that there was no difference in contraction velocity between patients who were successfully extubated, compared to those who were re-intubated [52]. It is not clear why there is such variation in results, and further research on conduction velocity is required, along with standardization whether velocity is measured over tidal or maximal inspiratory efforts. The same authors found that multiplying the diaphragmatic excursion $(E)$ by the inspiratory time $(I)$ to give a diaphragmatic excursiontime index gave values that were significantly higher in patients who had been successfully extubated compared to those who failed extubation [53]. The differences were still significant regardless as to whether the measurements were performed during spontaneous breathing or after extubation. However, significance was lost during pressure-assist ventilation modes.

Speckle tracking can detect tissue motion and distortion [54]. In healthy volunteers, it has been used to successfully assess diaphragmatic strain under pressure support ventilation [55] and was weakly but significantly associated with caudal diaphragm displacement [56]. This technique may provide useful information about the diaphragm during controlled mechanical ventilation, but as yet, there are no studies examining speckle tracking in the critical care population. Similarly, an "area method" [57] assessing diaphragm motion in two dimensions, correlates with lung volume using both $\mathrm{B}$ and $\mathrm{M}$-mode ultrasound in healthy volunteers, and can be performed on both sides of the chest.

Further research focuses on the prediction of successful extubation in particular patient groups. For example, a recent study demonstrated that diaphragm thickness measured before anesthetic induction correlates with time to extubation in patients undergoing liver transplants. Time to extubation after the procedure was higher in patients with pre-operative end expiratory diaphragm thickness of less than $2 \mathrm{~mm}$ [58].

In patients with Chronic Obstructive Pulmonary Disease (COPD), diaphragmatic ultrasound may predict successful weaning on one side, but could also serve to predict success of non-invasive ventilation. In this context, it has been reported that COPD patients with diaphragm dysfunction (diagnosed by a thickening fraction of less than $20 \%$ ), who require non-invasive ventilation, were 4.4 times more likely to need intubation, more often proceeded to tracheostomies, and had increased length of stay in ICU and hospital mortality [59]. These results were in line with an earlier smaller study that also 
described an association of diaphragm dysfunction with Non-Invasive Ventilation (NIV) failure and increased mortality [60]. However, reduced diaphragmatic thickening itself is not a risk factor for acute exacerbation of COPD [61].

\section{Conclusions}

Diaphragmatic ultrasound has been extensively studied as a predictor of successful weaning from mechanical ventilation, and continues to be studied. It remains difficult to draw general conclusions from individual studies due to the marked variation in study design and population. Even, definitions such as a failed breathing trial or failed extubation have not been standardized across studies, rendering comparison between outcome measures impossible. As yet, defined cut-offs for measurements of diaphragmatic ultrasound have been agreed, and there are no randomized control trials available. Although diaphragmatic ultrasound is a promising diagnostic tool, greater standardization of protocols, outcome measures and ventilatory settings is required for further research and clinical application.

\section{Abbreviations}

AUC: area under the curve; AUC-ROC: area under the curve (receiver-operator characteristic); COPD: Chronic Obstructive Pulmonary Disease; ICC: intra-class correlation coefficient; ICU: intensive care unit; NIV: non-invasive ventilation; SBT: spontaneous breathing trial; RSBI: Rapid Shallow Breathing Index.

\section{Authors' contributions}

PT wrote and devised the manuscript. SA provided the ultrasound images for the figures and assisted in the literature search. IW assisted in the editing and writing of the manuscript. All authors read and approved the final manuscript.

\section{Author details}

${ }^{1}$ Critical Care Unit, Royal Liverpool University Hospital, Liverpool, UK. ${ }^{2}$ Institute of Aging and Chronic Disease, University of Liverpool, Liverpool, UK. ${ }^{3}$ Institute of Infection and Global Health, University of Liverpool, Liverpool, UK.

\section{Acknowledgements}

None.

\section{Competing interests}

The authors declare that they have no competing interests.

\section{Availability of data and materials}

Not applicable.

\section{Consent for publication}

Not applicable.

\section{Ethical approval and consent to participate}

Not applicable.

\section{Funding}

Not applicable.

\section{Publisher's Note}

Springer Nature remains neutral with regard to jurisdictional claims in published maps and institutional affiliations.
Received: 21 December 2018 Accepted: 8 February 2019

Published online: 28 February 2019

\section{References}

1. Goligher EC, Dres M, Fan E, Rubenfeld GD, Scales DC, Herridge MS et al (2018) Mechanical ventilation-induced diaphragm atrophy strongly impacts clinical outcomes. Am J Respir Crit Care Med 197:204-213

2. Grosu HB, Lee Yl, Lee J, Eden E, Eikermann M, Rose KM (2012) Diaphragm muscle thinning in patients who are mechanically ventilated. Chest $142: 1455-1460$

3. Zambon M, Beccaria P, Matsuno J (2016) Mechanical ventilation and diaphragmatic atrophy in critically ill patients: an ultrasound study. Crit Care Med 43:29-38

4. Goligher EC, Fan E, Herridge MS, Murray A, Vorona S, Brade D et al (2015) Evolution of diaphragm thickness during mechanical ventilation. impact of inspiratory effort. Am J Respir Crit Care Med 192:1080-1088

5. Glau CL, Conlon TW, Himebauch AS, Yehya N, Weiss SL, Berg RA et al (2018) Progressive diaphragm atrophy in pediatric acute respiratory failure. Pediatr Crit Care Med 19:406-411

6. Cartwright MS, Kwayisi G, Griffin LP, Sarwal A, Walker FO, Harris JM et al (2013) Quantitative neuromuscular ultrasound in the intensive care unit. Muscle Nerve 47:255-259

7. Baldwin CE, Bersten AD (2014) Alterations in respiratory and limb muscle strength and size in patients with sepsis who are mechanically ventilated. Phys Ther 94:68-82

8. Doust BD, Baum JK, Maklad NF, Doust VL (1975) Ultrasonic evaluation of pleural opacities. Radiology 114:135-140

9. Matamis D, Soilemezi E, Tsagourias M, Akoumianaki E, Dimassi S, Boroli F et al (2013) Sonographic evaluation of the diaphragm in critically ill patients. Technique and clinical applications. Intensive Care Med 39:801-810

10. Testa A, Soldati G, Giannuzzi R, Berardi S, Portale G, Gentilone Silveri N et al (2011) Ultrasound M-mode assessment of diaphragmatic kinetics by anterior transverse scanning in healthy subjects. Ultrasound Med Biol 37:44-52

11. Houston JG, Morris AD, Howie CA, Reid JL (1992) Technical report: quantitative assessment of diaphragmatic movement-A reproducible method using ultrasound quantitative assessment of diaphragmatic movement a reproducible method using ultrasound. Clin Radiol 46:405-407

12. Scarlata S, Mancini D, Laudisio A, Benigni A, Antonellia Incalzi R (2018) Reproducibility and clinical correlates of supine diaphragmatic motion measured by $\mathrm{M}$-mode ultrasonography in healthy volunteers. Respiration 96:259-266

13. Boussuges A, Gole Y, Blanc P (2009) Diaphragmatic motion studied by M-mode ultrasonography: methods, reproducibility, and normal values. Chest 135:391-400

14. Houston JG, Angus RM, Cowan MD, McMillan NC, Thomson NC, Houston $M$ et al (1994) Ultrasound assessment of normal hemidiaphragmatic movement: relation to inspiratory volume. Thorax 49:500-503

15. Haji K, Royse A, Green C, Botha J, Canty D, Royse C (2016) Interpreting diaphragmatic movement with bedside imaging, review article. J Crit Care 34:56-65

16. Boon AJ, Harper CJ, Ghahfarokhi LS, Strommen JA, Watson JC, Sorenson EJ (2013) Two-dimensional ultrasound imaging of the diaphragm: quantitative values in normal subjects. Muscle Nerve 47:884-889

17. Cardenas LZ, Santana PV, Caruso P, Ribeiro de Carvalho CR, Pereira de Albuquerque AL (2018) Diaphragmatic ultrasound correlates with inspiratory muscle strength and pulmonary function in healthy subjects. Ultrasound Med Biol 44:786-793

18. Holtzhausen S, Unger M, Lupton-Smith A, Hanekom S (2018) An investigation into the use of ultrasound as a surrogate measure of diaphragm function. Heart Lung 47:418-424

19. Hellyer NJ, Andreas NM, Bernstetter AS, Cieslak KR, Donahue GF, Steiner EA et al (2017) Comparison of diaphragm thickness measurements among postures via ultrasound imaging. PM\&R 9:21-25

20. Vivier E, Roche-Campo F, Brochard L, Mekontso Dessap A (2017) Determinants of diaphragm thickening fraction during mechanical ventilation: an ancillary study of a randomised trial. Eur Respir J 50:1700783 
21. Vivier E, Dessap AM, Dimassi S, Vargas F, Lyazidid A, Thille AW et al (2012) Diaphragm ultrasonography to estimate the work of breathing during non-invasive ventilation. Intensive Care Med 38:796-803

22. Gursel G, Inci K, Alasgarova Z (2018) Can diaphragm dysfunction be reliably evaluated with pocket-sized ultrasound devices in intensive care Unit? Crit Care Res Pract. Article ID: 5192647

23. Dres M, Goligher EC, Dubé B-P, Morawiec E, Dangers L, Reuter D et al (2018) Diaphragm function and weaning from mechanical ventilation: an ultrasound and phrenic nerve stimulation clinical study. Ann Intensive Care 8:53

24. Houston JG, Fleet M, Cowan MD, McMillan NC (1995) Comparison of ultrasound with fluoroscopy in the assessment of suspected hemidiaphragmatic movement abnormality. Clin Radiol 50:95-98

25. Zambon M, Greco M, Bocchino S, Cabrini L, Beccaria PF, Zangrillo A (2017) Assessment of diaphragmatic dysfunction in the critically ill patient with ultrasound: a systematic review. Intensive Care Med 43:29-38

26. Llamas-Álvarez AM, Tenza-Lozano EM, Latour-Pérez J (2017) Diaphragm and lung ultrasound to predict weaning outcome. Chest 152:1140-1150

27. Li C, Li X, Han H, Cui H, Wang G, Wang Z (2018) Diaphragmatic ultrasonography for predicting ventilator weaning: a meta-analysis. Medicine (Baltimore) 97:e10968

28. Qian Z, Yang M, Li L, Chen Y (2018) Ultrasound assessment of diaphragmatic dysfunction as a predictor of weaning outcome from mechanical ventilation: a systematic review and meta-analysis. BMJ Open 8:21189

29. Goligher EC, Laghi F, Detsky ME, Farias P, Murray A, Brace D et al (2015) Measuring diaphragm thickness with ultrasound in mechanically ventilated patients: feasibility, reproducibility and validity. Intensive Care Med 41:642-649

30. Kim Y, Hee HJ, Suh J, Hong RSB, Koh Y, Lim CM (2011) Diaphragm dysfunction assessed by ultrasonography: influence on weaning from mechanical ventilation. Crit Care Med 39:2627-2630

31. Jiang JR, Tsai TH, Jerng JS, Yu CJ, Wu HD, Yang PC (2004) Ultrasonographic evaluation of liver/spleen movements and extubation outcome. Chest 126:179-185

32. Dinino E, Gartman EJ, Sethi JM, Mccool D (2014) Diaphragm ultrasound as a predictor of successful extubation from mechanical ventilation. Thorax 69:423-427

33. Ferrari G, De Filippi G, Fabrizio E, Panero F, Volpicelli G, Apra F (2014) Diaphragm ultrasound as a new index of discontinuation from mechanical ventilation. Crit Ultrasound J 6:8

34. Zhou P, Zhang Z, Hong Y, Cai H, Zhao H, Xu P et al (2017) The predictive value of serial changes in diaphragm function during the spontaneous breathing trial for weaning outcome: a study protocol. BMJ Open 7:e015043

35. Samanta S, Singh RK, Baronia AK, Poddar B, Azim A, Gurjar M (2017) Diaphragm thickening fraction to predict weaning - a prospective exploratory study. J Intensive Care 5:62

36. Blumhof S, Wheeler D, Thomas K, Mccool F, Mora J (2016) Change in diaphragmatic thickness during the respiratory cycle predicts extubation success at various levels of pressure support ventilation. Lung 194:519-525

37. Hayat A, Khan A, Khalil A, Asghar A (2017) Diaphragmatic excursion: does it predict successful weaning from mechanical ventilation? J Coll Physicians Surg Pak 27:743-746

38. Haji K, Royse A, Tharmaraj D, Haji D, Botha A, Royse C (2015) Diaphragmatic regional displacement assessed by ultrasound and correlated to subphrenic organ movement in the critically ill patients-an observational study. J Crit Care 30:439.e7-439.e13

39. Yoo J-W, Lee SJ, Lee JD, Kim HC (2018) Comparison of clinical utility between diaphragm excursion and thickening change using ultrasonography to predict extubation success. Korean J Intern Med 33:331-339

40. Dhungana A, Khilnani G, Hadda V, Guleria R (2017) Reproducibility of diaphragm thickness measurements by ultrasonography in patients on mechanical ventilation. World J Crit Care Med 6:185-189

41. Dres M, Dubé B-P, Mayaux J, Delemazure J, Reuted D, Brochard L et al (2017) Coexistence and impact of limb muscle and diaphragm weakness at time of liberation from mechanical ventilation in medical intensive care unit patients. Am J Respir Crit Care Med 195:57-66
42. Chien JY, Lin MS, Huang YCT, Chien YF, Yu CJ, Yang PC (2008) Changes in B-type natriuretic peptide improve weaning outcome predicted by spontaneous breathing trial. Crit Care Med 36:1421-1426

43. Luo L, Li Y, Chen X, Sun B, Li W, Gu W et al (2017) Different effects of cardiac and diaphragm function assessed by ultrasound on extubation outcomes in difficult-to-wean patients: a cohort study. BMC Pulm Med 17:161

44. Silva S, Ait Aissa D, Cocquet P, Hoarau L, Ruiz J, Ferre F et al (2017) Combined thoracic ultrasound assessment during a successful weaning trial predicts postextubation distress. Anesthesiology 127:666-674

45. Haji K, Haji D, Canty DJ, Royse AG, Green C, Royse CF (2018) The impact of heart, lung and diaphragmatic ultrasound on prediction of failed extubation from mechanical ventilation in critically ill patients: a prospective observational pilot study. Crit Ultrasound J 10:13

46. Yang KL, Tobin MJ, Presberg KW (1991) A prospective study of indexes predicting the outcome of trials of weaning from mechanical ventilation. N Eng J Med 324:1445-1450

47. Karthika M, Al Enezi FA, Pillai LV, Arabi YM (2016) Rapid shallow breathing index. Ann Thorac Med 11:167-176

48. Epstein SK (1995) Etiology of extubation failure and the predictive value of the rapid shallow breathing index. Am J Respir Crit Care Med 152:545-549

49. Banerjee A, Mehrotra G (2018) Comparison of lung ultrasound-based weaning indices with rapid shallow breathing index: are they helpful? Indian J Crit Care Med 22:435-440

50. Pirompanich P, Romsaiyut S (2018) Use of diaphragm thickening fraction combined with rapid shallow breathing index for predicting success of weaning from mechanical ventilator in medical patients. J intensive care 6:6

51. Huang D, Ma H, Zhong W, Wang X, Wu Y, Qin T et al (2017) Using M-mode ultrasonography to assess diaphragm dysfunction and predict the success of mechanical ventilation weaning in elderly patients. J Thorac Dis 9:3177-3186

52. Palkar A, Mayo P, Singh K, Koenig S, Narasimhan M, Singh A et al (2018) Serial diaphragm ultrasonography to predict successful discontinuation of mechanical ventilation. Lung 196:363-368

53. Palkar A, Narasimhan M, Greenberg H, Singh K, Koenig S, Mayo P et al (2018) Diaphragm excursion-time index: a new parameter using ultrasonography to predict extubation outcome. Chest 153:1213-1220

54. Haaksma M, Roel Tuinman P, Heunks L (2017) Ultrasound to assess diaphragmatic function in the critically ill-a critical perspective. Ann Transl Med 5:114

55. Hatam N, Goetzenich A, Rossaint R et al (2014) A novel application for assessing diaphragmatic function by ultrasonic deformation analysis in noninvasively ventilated healthy young adults. Ultraschall der Medizin Eur J Ultrasound 35:540-546

56. Orde SR, Boon AJ, Firth DG, Vilarrage HR, Sekiguchi H (2015) Diaphragm assessment by two dimensional speckle tracking imaging in normal subjects. BMC Anesthesiol 16:43

57. Skaarup SH, Løkke A, Laursen CB (2018) The Area method: a new method for ultrasound assessment of diaphragmatic movement. Crit Ultrasound J 10:15

58. Sharma A, Karna ST, Tandon M, Pandey CK, Chaturvedi R, Vyas V et al (2018) Use of ultrasound-guided preoperative diaphragmatic thickness as a predictor of postoperative weaning failure in recipients and donors scheduled for living donor liver transplant surgery. Saudi J Anaesth 12:406-411

59. Marchioni A, Castaniere I, Tonelli R, Fantini R, Fontana M, Tabbi L et al (2018) Ultrasound-assessed diaphragmatic impairment is a predictor of outcomes in patients with acute exacerbation of chronic obstructive pulmonary disease undergoing noninvasive ventilation. Crit Care 22:109

60. Antenora F, Fantini R, lattoni A, Castaniere I, Sdanganelli A, Livrieri F et al (2017) Prevalence and outcomes of diaphragmatic dysfunction assessed by ultrasound technology during acute exacerbation of COPD: a pilot study. Respirology 22:338-344

61. Eryüksel E, Cimşit C, Bekir M, Cimsit C, Karakurt S (2017) diaphragmatic thickness fraction in subjects at high-risk for COPD exacerbations. Respir Care 62:1565-1570 